\title{
Patients with papillary thyroid carcinoma associated with high stimulated serum calcitonin levels
}

\author{
Kursad Unluhizarci', Hulya Akgun², Bahadır Oz³, Zuleyha Karaca', Fatih Tanriverdi' and \\ FahrettinKelestimur ${ }^{1}$
}

Departments of 'Endocrinology, 2Pathology, and 3Surgery, Erciyes University Medical School, Kayseri, Turkey
Correspondence

should be addressed

to K Unluhizarci

Email

kursad@erciyes.edu.tr

\section{Summary}

Among various substances produced by C-cells, the most important one is calcitonin (CT) that is used for detection, postoperative follow-up and evaluation of individuals at risk of developing medullary thyroid carcinoma (MTC). However, the role of serum CT measurement in the evaluation of thyroid nodules has been widely discussed, and there is still no consensus about the role of $\mathrm{CT}$ in the initial evaluation of all thyroid nodules. Two patients with thyroid nodules whose fine-needle aspiration results were compatible with benign cytology besides having mildly elevated basal serum calcitonin levels were reported. Calcitonin responses (peak levels were 313 and $229 \mathrm{pg} / \mathrm{mL}$, respectively) to calcium stimulation test were compatible with the possible diagnosis of MTC. However, the final diagnosis was papillary thyroid carcinoma of the thyroid gland. There are limited numbers of case reports showing such an increased serum calcitonin responses to calcium stimulation test associated with papillary or follicular thyroid carcinoma of the thyroid. We suggest to measure serum CT level once and in case of normal levels, no further CT measurement is necessary. Physicians should keep in mind that thyroid carcinomas other than MTCs may also be associated with high serum CT levels.

\section{Learning points:}

- Although serum calcitonin is a valuable tumor marker for MTC, it is well known that mild elevations may be seen in some other diseases such as Hashimoto thyroiditis, neuroendocrine tumors or due to medications such as proton pump inhibitors, calcium salts, beta blockers and glucocorticoids.

- Those two cases indicate that high calcitonin responses to calcium stimulation test, mimicking MTC, may also be seen in patients with papillary thyroid carcinoma although the mechanism is not clear.

\section{Background}

Medullary thyroid carcinoma (MTC) is a neoplasia of parafollicular cells, which represents approximately $4 \%$ of malignant thyroid tumors (1). Approximately 75\% are sporadic and $25 \%$ are inherited (1). MTC diagnosis is usually delayed, and its prognosis can be altered by earlier detection. Thus, serum calcitonin (CT) measurements have been suggested as a screening test for MTC in all thyroid solid or cystic-solid nodules (2). The role of serum CT measurement in the evaluation of thyroid nodules has been widely discussed, and there is still no consensus about the role of CT in the initial evaluation of all thyroid nodules. Apart from problems related to cost-to-benefit ratio, false positives and low prevalence of MTC are the main factors considering CT measurement as an unnecessary tool for the investigation of a thyroid nodule. 
In this case report, our aim is to present a mildly elevated basal serum calcitonin level associated with very high levels of stimulated serum CT responses may be seen in patients with papillary thyroid carcinoma, which justifies the routine CT measurement from another point of view, in the evaluation of a patient with thyroid nodule.

\section{Case presentations}

\section{Case 1}

A 36-year-old man sought medical advise because of thyroid nodule detected during a clinical examination for an unrelated condition. Physical examination was unremarkable including nonpalpable thyroid gland. Thyroid ultrasonography revealed $18 \mathrm{~mm}$ solid nodule (isoechoic nodule with hypoechoic peripheral halo) in the left lobe of the thyroid gland. Serum TSH, free $\mathrm{T} 3$ and free T4 levels were within normal limits. Antithyroglobulin and anti-thyroperoxidase antibodies were not available. Since basal CT level was mildly elevated $(18 \mathrm{pg} / \mathrm{mL})$, calcium stimulation test was performed for calcitonin response (Table 1). Thyroid nodule fine-needle aspiration (FNA) was done under direct visualization with ultrasound and the cytology was compatible with 'lymphocytic thyroiditis'. The patient underwent a total thyroidectomy for the possible diagnosis of MTC because of remarkably high serum CT responses to calcium stimulation test. Histopathologic diagnosis was 'papillary thyroid carcinoma, follicular variant, $12 \mathrm{~mm}$ in size', as shown in Fig. 1A.

\section{Case 2}

A 44-year-old woman was admitted to the hospital with nonspecific complaints such as back and epigastric pain and dyspnea for three months. Her physical examination was normal except a palpable thyroid nodule in the right lobe. Serum TSH, free T3 and free T4 levels were within normal limits. Thyroid nodule FNA was done under direct visualization with ultrasound and the diagnosis was 'benign lesion'. Since basal CT level was mildly elevated $(13 \mathrm{pg} / \mathrm{mL})$, calcium stimulation test was

Table 1 Basal and stimulated serum calcitonin levels $(\mathrm{pg} / \mathrm{mL})$ during calcium stimulation test.

\begin{tabular}{|c|c|c|c|c|c|}
\hline & Basal & $1 \mathrm{~min}$ & $3 \mathrm{~min}$ & $5 \mathrm{~min}$ & $10 \mathrm{~min}$ \\
\hline Case 1 & 18 & 240 & 313 & 256 & 179 \\
\hline Case 2 & 13 & 215 & 229 & 177 & 123 \\
\hline
\end{tabular}
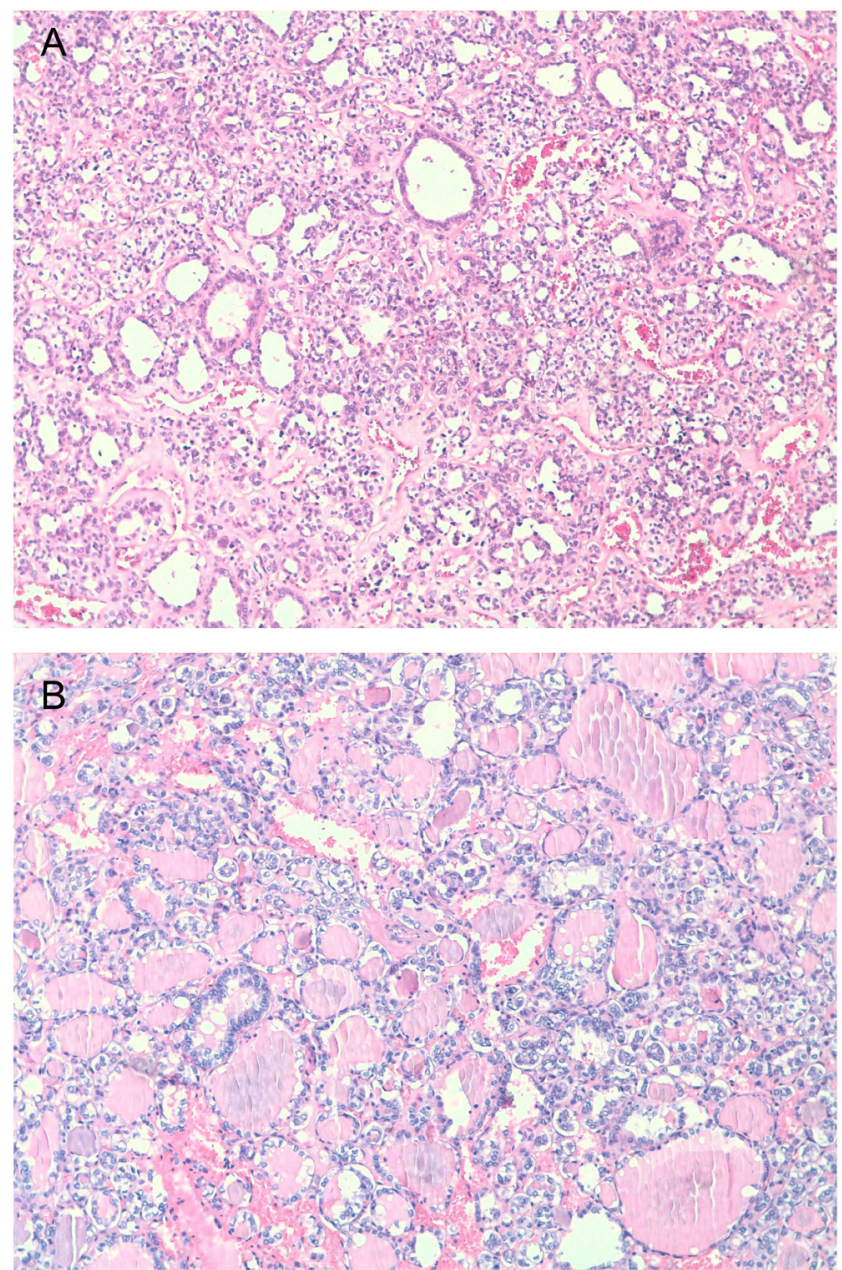

Figure 1

Follicular variant papillary thyroid carcinoma cells demonstrating ground glass nuclei and nuclear overlapping (H\&E $\times 100)$ in case 1 (A), and in case 2 (B).

performed for calcitonin response (Table 1). The patient underwent total thyroidectomy for the possible diagnosis of MTC. Histopathologic diagnosis was 'papillary thyroid carcinoma, follicular variant, 17 and $10 \mathrm{~mm}$ in sizes', as shown in Fig. 1B.

Both patients gave their informed consent for the presentation of their data in the scientific manuscript.

\section{Investigation}

Calcium stimulation test was done with the intravenous infusion of calcium gluconate $(2-2.5 \mathrm{mg} / \mathrm{kg}$ of elemental calcium) for stimulated serum CT levels. Serum CT was measured by an immunochemiluminescent assay (Immulite, Siemens Healthcare Diagnostic Products Ltd, Lianberis, Gwynedd LL55 4EL, UK) with a reference values of up to $5 \mathrm{pg} / \mathrm{mL}$ for women and $8.4 \mathrm{pg} / \mathrm{mL}$ for men. 


\section{Treatment}

Both patients had total thyroidectomy as indicated earlier.

\section{Outcome and follow-up}

Case 1 is free of any symptoms and signs for thyroid papillary carcinoma at fifth year of his diagnosis. Case 2 received a course of radioactive iodine (RAI) ablation therapy five years ago, and she is free of any signs and symptoms since then.

\section{Discussion}

MTC is a malignant tumor originating from thyroid parafollicular C-cells and accounts for approximately $4 \%$ of thyroid cancers. Among various substances produced by C-cells the most important one is CT that is used for detection, post-operative follow-up and evaluation of individuals at risk of developing MTC. However, the role of serum CT in the evaluation of thyroid nodules has been widely discussed, and there is still no consensus regarding the role of blood CT measurement in the initial evaluation of all thyroid nodules.

When MTC is detected in the form of a thyroid nodule, it is usually associated with metastases (3). Therefore, early diagnosis is fundamental to improve survival rates. Thus, one way of early diagnosis is to measure basal serum CT levels, which should be further evaluated by pentagastrin or calcium stimulation tests in patients with mildly elevated serum CT levels (4). Additionally, the measurement of CT in washout fluids of thyroid nodule aspirate may be valuable in inconclusive patients. As occurred in our patients, FNA in the diagnosis of medullary neoplasia has a limited value and about less than half of the cases of MTC can be diagnosed with FNA. Surgery was advised to the presented patients since they had elevated calcitonin levels and peak calcitonin response of $>100 \mathrm{pg} / \mathrm{mL}$ to calcium stimulation test despite having benign cytology of thyroid nodules. It has been suggested that, as soon as stimulated CT peaks of over $100 \mathrm{pg} / \mathrm{mL}$ are documented, total thyroidectomy and bilateral central neck (level VI) dissection should be discussed with the patient (5). However, it has been shown that only $10-40 \%$ of all patients with high levels of CT is associated with a thyroid nodule actually have MTC (6).

The first patient has the diagnosis of 'lymphocytic thyroiditis' in FNA, but very high levels of CT to calcium stimulation test led to operate the patient. Unfortunately, thyroid antibodies were not available after cytological diagnosis of lymphocytic thyroiditis also. Chronic autoimmune thyroiditis has been suggested as a cause of increased serum CT levels, however, no general consensus has been achieved regarding the levels of CT in Hashimoto's thyroiditis (7). The limited secretory reserve of CT noted in those patients may be a consequence of a progressive C-cell destruction following nonspecific follicular and parafollicular cell damage caused by lymphocytic infiltration of the thyroid gland. Hashimoto's thyroiditis should be considered in the differential diagnosis in patients with moderately elevated serum CT levels. However, in our patient, a remarkably high CT response to calcium stimulation test cannot be explained by 'lymphocytic thyroiditis', which led us to conclude surgery. Thyroid nodules with positive calcium stimulation tests suggesting MTC and showing only thyroiditis at histology is not a usual condition.

In the second case, the patient was admitted to the hospital for nonspecific symptoms and only a palpable thyroid nodule led us to reach the final diagnosis. Although FNA revealed a benign cytology, mildly elevated serum CT in association with a very high stimulated CT level led us to suggest surgery to the patient. No ectopic CT-producing tumors were found in both patients such as neuroendocrine tumors and none of the patients were smoking or using any drug, such as beta blockers, calcium salts, glucocorticoids, proton pump inhibitors, affecting serum CT level.

An effective screening method leading to an early diagnosis may be able to modify the prognosis of MTC. Routine use of serum CT followed by a confirming stimulation test in the cases of high basal levels is the most recommended approach due to low accuracy of FNA in the diagnosis of MTC. The pentagastrin test has largely been used for many years to stimulate serum CT. The unavailability of pentagastrin in the United States and also in most European countries recently raised to meet other methods. Calcium stimulation test has been demonstrated to represent a good choice to stimulate serum CT (8). It has been suggested that pentagastrinstimulated CT values higher than $100 \mathrm{pg} / \mathrm{mL}$ is a strong evidence for MTC (8). However, a lot of discussion is still present regarding the peak value of serum CT after calcium stimulation test $(8,9)$. Niederle B suggested that, although experience with use of calcium for stimulation of CT has been limited, stimulated peaks of over $100 \mathrm{pg} /$ $\mathrm{mL}$ should raise the surgical option (9).

Although our CT results may be considered as false positive for the diagnosis of MTC, we are satisfied that the test worked well and diagnosed two papillary carcinoma 
patients relatively earlier. It is also important to note that papillary thyroid carcinoma was not detected during FNA, which is a well-established method for diagnosing thyroid tumors, because of its high level of accuracy in predicting papillary thyroid carcinoma and has become an important initial modality for assessing the requirement for surgical resection of thyroid tumors. Follicular and papillary thyroid carcinomas have been reported to be associated with C-cell hyperplasia and high levels of serum CT levels (6). It has been proposed that these tumors may release substances that possess a paracrine stimulatory action on the C-cells and will thus eventually raise serum calcitonin levels (10). In the current literature, there is only one case report showing an increased serum calcitonin responses to calcium stimulation test associated with occult papillary thyroid carcinoma of the thyroid and C-cell hyperplasia (11). However, there were no C-cell hyperplasia in our patients.

In conclusion, we suggest that, in all cases with nodular thyroid disease, but not in every visit, serum CT should be measured once and in case of normal levels, no further CT measurement is necessary. All the patients with increased levels of serum CT should be investigated carefully in order to rule out conditions other than MTC. Physicians should keep in mind that thyroid carcinomas other than MTC may also associate with high serum CT levels.

\section{Declaration of interest}

The authors declare that there is no conflict of interest that could be perceived as prejudicing the impartiality of the research reported.

\section{Funding}

This research did not receive any specific grant from any funding agency in the public, commercial or not-for-profit sector.

\section{Patient consent}

Written informed consent has been obtained from the patients for publication of the submitted article and accompanying images.

\section{Author contribution statement}

Kursad Unluhizarci: Physician of the patients, drafting the article; Hulya Akgun: Histopathologic evaluations; Bahadır Öz: Surgeon; Zuleyha Karaca: Follow-up (first two years); Fatih Tanriverdi: Follow-up (last three years); Fahrettin Kelestimur: Substantial contribution to the conception of the study, revising the manuscript.

\section{References}

1 Pappa T \& Alevizaki M 2016 Management of hereditary medullary thyroid carcinoma. Endocrine 53 7-17. (doi:10.1007/s12020-0160873-1)

2 Ozgen AG, Hamulu F, Bayraktar F, Yılmaz C, Tuzun M, Yetkin E, Tuncyurek M \& Kabalak T 1999 Evaluation of routine basal serum calcitonin measurement for early diagnosis of medullary thyroid carcinoma in seven hundred seventy-three patients with nodular goiter. Thyroid 9 579-582. (doi:10.1089/thy.1999.9.579)

3 Hahm JR, Lee MS, Min YK, Lee MK, Kim KW, Nam SJ, Yang JH \& Chung JH 2001 Routine measurement of serum calcitonin is useful for early detection of medullary thyroid carcinoma in patients with nodular thyroid diseases. Thyroid 11 73-80. (doi:10.1089/10507250150500694)

4 Elisei R, Bottici V, Luchetti F, Di Coscio G, Romei C, Grasso L, Miccoli P, Iacconi P, Basolo F, Pinchera A, et al. 2004 Impact of routine measurement of serum calcitonin on the diagnosis and outcome of medullary thyroid cancer: experience in 10864 patients with nodular thyroid disorders. Journal of Clinical Endocrinology and Metabolism 89 163-168. (doi:10.1210/jc.2003-030550)

5 Trimboli P, Giovanella L, Crescenzi A, Romanelli F, Valabrega S, Spriano G, Cremonini G, Guglielmi R \& Papini E 2014 Medullary thyroid cancer diagnosis: an appraisal. Head and Neck 36 1216-1223. (doi:10.1002/hed.23449)

6 Borget I, De Pouvourville G \& Schlumberger M 2007 Editorial: Calcitonin determination in patients with nodular thyroid disease. Journal of Clinical Endocrinology and Metabolism 92 425-427. (doi:10.1210/jc.2006-2735)

7 Barbot N, Guyetant S, Beldent V, Akrass A, Cerf I, Perdrisot R \& Bigorgne JC 1991 Chronic autoimmune thyroiditis and C-cell hyperplasia. Study of calcitonin secretion in 24 patients. Annals of Endocrinology 52 109-112.

8 Fugazzola L 2013 Stimulated calcitonin cut-offs by different tests. European Thyroid Journal 2 49-56. (doi:10.1159/000346020)

9 Niederle B 2014 Screening for medullary carcinoma of the thyroid. British Journal of Surgery 101 1625-1626. (doi:10.1002/bjs.9652)

10 Toledo SPA, Lourenco DM Jr, Santos MA, Tavares MR, Toledo RA \& Correia-Deur JE 2009 Hypercalcitoninemia is not pathognomonic of medullary thyroid carcinoma. Clinics $\mathbf{6 4} 699-706$. (doi:10.1590/ s1807-59322009000700015)

11 Batista RL, Toscanini AC, Brandao LG \& Cunha-Neto MBC 2013 False positive results using calcitonin as a screening method for medullary thyroid carcinoma. Indian Journal of Endocrinology and Metabolism 17 524-528. (doi:10.4103/2230-8210.111677)

Received in final form 5 September 2017 Accepted 17 October 2017 